This is an accepted manuscript of an article to appear in Volume 92 of Philosophy. For citations, please use the published article.

\title{
Guilt, Practical Identity, and Moral Staining
}

\begin{abstract}
:
I argue for a view of guilt as moral staining similar to that propounded by Gabrielle Taylor (1985). I contend the view is more accurate than the model of guilt as the severance of valued relationships favored by Herbert Morris (1976). Adding to the interest of the subject, I consider both views on guilt as alternative ways of explaining the importance and priority of the ethical. On this front, Morris' relationship theory is congruent with how Scanlon (1998) accounts for the special force of moral reasons--they are about what we owe to each other. Taylor's staining view, on the other hand, is more in keeping with the claims of Ewing (1947) that breaches of moral obligation are more grave because they make us "evil in a way different than that in which pain is evil.”
\end{abstract}

It is common to distinguish the use of "ought" to express a moral obligation from its use to express a conclusion about what it would be rational, perhaps merely prudent, to do. The former we take to be graver than the latter. A.C. Ewing wrote of moral obligations, "We feel that we are under binding laws which we cannot break without being ourselves evil in a more serious and quite different way from that in which pain is evil.” ${ }^{1}$ He struggles here to articulate what makes moral duty so important, what makes immoral actions so serious.

T.M. Scanlon speaks of two questions around morality: priority and importance. The question of priority asks why it is that moral obligations are thought to take precedence over other reasons for actions. ${ }^{2}$ The issue of importance refers to why we feel that violations of obligation make a person subject to special disapprobation, up to and including punishment. ${ }^{3}$ Scanlon concludes that moral obligations have priority and importance because they concern

\footnotetext{
${ }^{1}$ A.C. Ewing, The Definition of GoOd 133 (1947).

${ }^{2}$ T.M. SCANLON, WHAT WE OWE TO EACH OTHER 160 (1998).

${ }^{3}$ Id. at $158-60$.
} 
what we owe to others. When we fail in them, we act in ways that cannot be justified to others and experience a distressing estrangement from our fellow humans (163). ${ }^{4}$

Ewing's words point us elsewhere: it is not our relationships with others that are marred by wrongdoing but our selves. Wrongdoing renders you evil—it may follow that this estranges you from your fellows—-but in the first instance it is you that are changed not your relationships. How we are rendered evil Ewing cannot say, only that it is a different way of being evil than that in which pain is evil. At this juncture, the idea of sin and the idea of karma come to mind.

In this paper, I offer an interpretation of how it is that breaches of moral obligation render one evil. My model is familiar from the literature on guilt. Gabriele Taylor has persuasively argued that guilt differs from shame and remorse in being concerned with (1) the idea that one has violated an obligation and (2) the idea that the violation has stained or disfigured the self. There is also in the guilt literature a prominent view that coheres with Scanlon's relationship theory. Herbert Morris has argued for the view that guilt is concerned with (1) violation of obligation and (2) the severance of valued relationships.

For the reasons that follow, I believe that Taylor's view of guilt is superior to that of Morris. I think that a model of guilt as moral staining better captures guilt's reflexive, firstpersonal character than a relationship-severance model. It also has the potential to explain the importance and priority of moral obligation by linking violations of duty with threats to one's personal identity. This is because, as Christine Korsgaard has argued, it is through our actions that we construct our personal or practical identities. Immoral actions leave stains that threaten your integrity because, like all other actions, they contribute a piece to the ongoing project of

\footnotetext{
${ }^{4}$ Id. at 163 .
} 
self-constitution. As we will see, a threat to the integrity of personal identity is existential peril; wrongdoing compromises the self and leads the agent to despair over the loss of self. My suggestion is that this despair is the evil that Ewing was baffled to name: the evil that is more serious and quite different from the evil of pain.

To illustrate these points, I offer an explanation of what I call “scrupulousness.” As I will shortly show, the scrupulous person-one who is persistently anxious about whether a minor action was right or wrong-is concerned with the possibility that the action has left her morally stained.

\section{A Problem}

\section{A. The Scrupulous Student}

Imagine a high school student sitting down for a geography test. Before the bell rings, she looks over the map of the world one last time before cramming the book back into her open backpack. During the test, while puzzling about the name of that country which sits below Kazakhstan and west of Uzbekistan, she idly glances downward. To her chagrin, the book is sitting half open and she spies the name of the country, "Kyrgyzstan." "What should I do?” she wonders. "The name was on the tip of my tongue; I was just about to remember.” So she decides to write “Kyrgyzstan.”

But then she pauses. "Maybe the answer wouldn’t have come to me. The right thing to do is leave the question blank.” "But I studied so much,” she retorts, "I'm sure I would've gotten the right answer on my own eventually. Why should I self-handicap like that?” So she scribbles “Kyrgyzstan” in the blank and finishes the exam. Still, she can’t help rehearsing these arguments, both when she gets home that night and when her exam is returned the next day with a shiny red A in the margin. She is worried-worried that what she did was wrong. She asks herself, "Was what I did cheating? Do I need to confess, or would that be absurd?” Attempting to 
answer her question, she might reason, “Well, I didn’t look at the book on purpose and I would've got the answer anyway.” However, the next moment she says to herself, "It doesn't matter if you did it on purpose or not; you had an unfair advantage. Besides, you can’t be sure whether you would've remembered that name.” Suppose she carries on fretting like this all week and that six months later she has to shake the thought out of her head to avoid bringing on another round of casuistry. All that fuss over a (perhaps innocent) answer on a high school geography exam!

Henceforth, I will use the word “scrupulousness” to identify the student's psychological state of retrospective anxiety and doubt. I adopt the word "scrupulous" because it suggests traits I wish to discuss, namely, the student's anxiety and doubt about the morality of her minor past actions.

\section{B. A Proposed Explanation}

My immediate goal in this paper is to explain scrupulousness. Specifically, why is it that the possibility of a small ethical infringement can occasion so much anxiety after the act? What is it about the uncertainty surrounding a single possible transgression, however so slight, that can cause people like the student to second guess themselves and question whether what they did was right long after the event has passed?

I propose that scrupulousness derives from anxiety about the effect of immoral actions on one's self. The idea is that unethical deeds leave one changed for the worse. Obviously, you bear a specific relationship to a past misdeed: you are the person who at time $t$ did immoral action $x$. However, I have in mind something different. There is a further, non-relational fact about your present state: you are somehow stained by the blameworthy action. On my model, scrupulousness is a manifestation of anxiety about the ethical staining of the self. The scrupulous 
person is unsure whether what he did was wrong, and in his uncertainty, he fears the worst, fears that acting unethically has tainted him.

The notion that wrongdoing leaves one morally stained is congruent with Gabriele Taylor’s theory of guilt. In her book, Pride, Shame, and Guilt, she observes, “[W]hen feeling guilty I think of myself as having brought about a forbidden state of affairs and thereby in this respect disfigured a self which otherwise remains the same." ${ }^{5}$ Unlike shame in which the person experiencing it feels inferior as a whole, the guilty person sees himself as having disfigured himself by an isolated violation of obligation: "Guilt is a burden he [the guilty person] has to carry, he cannot disown it, it must leave its mark upon him.”6

In the early going, I want to distinguish the notion of staining from a more familiar idea prominent in the virtue ethics tradition. The staining that is of concern to the scrupulous person is not the degradation of character that the virtue ethicist believes proceeds from bad actions. The worry is not that bad actions will turn into bad habits of thought, feeling, and action but that the bad action itself has simply left a black mark. Our student (let's call her Emily) is plainly a young woman of good character in the virtue ethical sense; after all, the vicious person is neither so attentive to ethical matters nor as self-critical when it comes to her own peccadilloes. Whichever way she chooses to respond to her worries, Emily is not about to become a serial cheater or routine liar. As such, her concern is not with the effects that cheating would have on her future dispositions but on the effect that the possible ${ }^{7}$ act of cheating may have had on her

\footnotetext{
${ }^{5}$ Gabriele Taylor, Pride, Shame, And Guilt: Emotions of SELF-Assessment 92 (1985).

${ }^{6} I d$.

${ }^{7}$ It's important to recognize that Emily is truly in doubt as to whether her action was right or wrong. Thus, when I use the word "possible," I mean to say that it is uncertain, at least to Emily, whether her actions were right or wrong. Moreover, I myself take it that it is not obvious whether what Emily did was right or wrong.
} 
self. She worries about the propriety of her actions because she worries that—although she may go on to live a virtuous life, disdaining dishonesty of every sort—she will henceforth be tainted by the act of cheating.

Nor is Emily concerned about what the action reveals about her character; she is not worried that her character is not what she thought it was. She has not discovered that she is dishonest—if anything, her aversion to cheating is now shining most strongly. Her action, we may suppose, is unquestionably out of character for her. As we will later see, it was her choice that concerns her-a choice that was not a mere result of facts about her character.

If moral staining is not to be explained in terms of the development of a vicious character, then how should we understand it? According to the proposed theory, immoral actions somehow change a person for the worse. Accordingly, there must be something about the person going forward that is altered, something that corresponds to the stain. However, if we have ruled out the development of bad psychological traits as the change involved, then it is hard to identify a suitable candidate. Once changes in a person's thoughts, feelings, and habits are set aside, what it means for a person to be stained by an unethical action is difficult to grasp.

\section{Korsgaard and Practical Identity}

The above remains long on metaphor and short on explanation. To flesh out the imagery, we can use Christine Korsgaard's work on practical identity to explain how bad actions taint the self. However, employing Korsgaard requires some exegetical labor. In what follows, I summarize Korsgaard's thinking about practical identity as presented in Self-Constitution: Agency, Identity, and Integrity. 
In brief, practical identity is the same thing as personal identity. ${ }^{8}$ That sounds simple enough, but Korsgaard also thinks that a person's practical identity is constructed by her choices. Unlike her identity as an animal or a living thing, her practical identity is up to her. She can build her personal/practical identity in this way because she is rational, which allows her to reflect on and choose the principles of her actions. Indeed, Korsgaard tells us that personal identity is composed—literally made up of—one’s actions.

Korsgaard's claim that we construct our practical/personal identities by our choices relies on a notion of personhood developed from her reading of Aristotle. In her mind, "The identity of a person, of an agent, is not the same as the identity of the human animal on whom the person normally supervenes." ${ }^{9}$ To understand the view, recall that Aristotle divided the living world into three forms of life: the vegetative, the animal, and the rational. ${ }^{10}$ The vegetative life of nutrition and reproduction, which is shared by all plants and animals, lies at the bottom. The intermediate animal form, characterized by "perception and sensation," is shared by humans and the other animals. ${ }^{11}$ Thanks to these distinctive abilities, humans and animals possess a kind of identity (animal identity) that plants lack. ${ }^{12}$ Atop the ladder, humans participate in the life of rational activity. This form of life is the source of practical identity. Just as an animal possesses a kind of identity that a plant lacks, so do humans possess a kind of identity that animals lack. Although humans still participate in the animal and vegetative forms of life, their participation in the

\footnotetext{
${ }^{8}$ Indeed, Korsgaard uses the phrases "practical identity" and "personal identity" interchangeably. See, e.g., CHRISTINE KORSGAARD, SELF-CONSTITUTION: AGENCY, IDENTITY, AND INTEGRITY 7 (2009).

${ }^{9}$ Id. at 19.

${ }^{10} I d$. at $127-29$.

${ }^{11} I d$. at 129.

${ }^{12} I d$.
} 
rational form of life allows them to construct personal or practical identities over and above their identities as animals or living things. ${ }^{13}$

Rationality entails the ability to construct one's personal identity because it means being able to choose the principles of one's actions, à la Kant. For an animal, its instincts are its principles of action. ${ }^{14}$ Instincts are principles because they determine how the animal will respond to the incentives that it experiences: "They are the laws of [the animal's] causality in the sense that they determine what she does for the sake of what.” ${ }^{15}$ In contrast, although humans possess instincts, ${ }^{16}$ they are also capable of acting in accordance with rational principles of their own choice and devise. ${ }^{17}$ By adopting a principle, we sanction it as a law for our will in the same way that an animal's instincts are a law to it. ${ }^{18}$

The process of deliberating upon and selecting the principles of our actions is the work of self-constitution. ${ }^{19}$ Personal identity "is constituted by our chosen actions." ${ }^{20}$ Note that Korsgaard uses the word "constituted" rather than "constructed." This is because personal identity is not just the result of our actions; it is composed of our actions. Actions are the bricks of which the house of personal identity is formed. Korsgaard goes so far as to tell us that "they [our actions] are us, because we are what we do."21 She explains:

When you deliberately decide what sorts of effects you will bring about in the world, you are also deliberately deciding what sort of a cause you will be. And that means you are deciding who you are. So we are each faced with the task of constructing a peculiar, individual kind of identity—-personal or practical identity—-that the other animals lack.

\footnotetext{
${ }^{13} I d$. at 128.

${ }^{14} \mathrm{Id}$. at 110.

${ }^{15} \mathrm{Id}$.

${ }^{16} I d$. at 116.

${ }^{17}$ Id. at 110 .

${ }^{18} \mathrm{Id}$. at 116.

${ }^{19} \mathrm{Id}$. at $19-20$.

${ }^{20} \mathrm{Id}$. at 130 .

${ }^{21} \mathrm{Id}$.
} 
$\cdots$

It is as the possessor of personal or practical identity that you are the author of your actions, and responsible for them. And yet at the same time it is in choosing your actions that you create this identity. What this means is that you constitute yourself as the author of your actions in the very act of choosing them. ${ }^{22}$

Given this connection between freedom, action, and self-constitution, Korsgaard's theory is ripe for application to the problem of moral staining.

\section{Applying the Theory}

Ethical staining is easy to understand if one accepts Korsgaard’s practical identity theory. Our practical identities are constructed by our choices. When we choose to act unethically, we are like craftsmen inserting rotten timbers into a frame house. Our work is thus sullied in the same way that the work of a cook who pours a spot of rancid milk into the soup mars his own labors. Like the soup, the self is a work-in-progress to which many ingredients have been added. One does not become a wicked person by one wicked action, but like the soup, one nonetheless has at least one undeniably bad element composing oneself. The ethical stain that bad actions leave is just their contribution, a few shoddy nails and boards, to the ongoing process of selfconstruction. When we choose to do wrong, we reshape ourselves, however so little, for the worse.

Scrupulousness is anxiety about the contributions that immoral actions make to selfconstruction. When we act unethically, we are shaping ourselves for the worse. It is only natural that we worry. When our young student is fretting about the ethics of her exam taking, she is worried that she has altered herself in a bad way by her actions. This is not a possibility that she regards as one would regard a mere historical fact. Rather, she looks at the possibility with apprehension because it means that she may be a person partly composed by a bad action. Her

${ }^{22}$ Id. at $19-20$. 
misdeed then is not just a past fact—-the fact that at time $x$ she performed immoral action $y$-but a present reality.

The difference between regarding your immoral actions as past facts and seeing them as part of you in the present is a substantial one. The latter holds your attention and cries out for expiation in a way that the former does not. The former may be brushed aside, treated as errors that should only be dwelled upon to the extent that reflecting on them will help you avoid making the same mistakes in the future. The latter, on the other hand, are matters of pressing concern in the present. If immoral actions leave one stained, then the platitudes about "learning from your mistakes and moving on" cannot be credited without reservation. This is because poring over one's past misdeeds is not just idle retrospection but consists in facing what is a persistent part of oneself. Thus, to look over past blameworthy acts is not idle; at a minimum, it is needed for honest self-appraisal. Moreover, it may be important for expiation, insofar as that is possible or desirable.

The impact of bad actions on who you are goes a long way to explaining scrupulousness. Someone like our student worries about the ethics of what she did because ethical staining is a grave prospect, a prospect that both drives her to find an answer to the question, "Was what I did wrong?” and makes her afraid of the answer. When looking back on an ethically ambiguous situation, our student feels compelled both to conduct an honest, uncompromising investigation and to mount a vigorous defense of herself. This accounts for why she cannot help but keep rehashing the events of the exam along with the relevant ethical considerations. Her obsessive exercises in applied ethics are driven by a desire (grounded in anxiety over what the answer might be) to know whether or not she has stained herself. Her worried mulling bears the relief of exoneration in one hand and the pain of encountering the ethical black mark in the other. Further, 
her task is made all the more maddening insofar as she knows to distrust herself as one sitting as judge over her own cause. Recognizing this tangle of emotions helps explain why she would spend so much time — even drive herself to distraction months later—-thinking about such a slight ethical peccadillo, one which might not even be a peccadillo but be completely innocent.

I want now to bring out two additional ideas about ethical staining and crystallize them with the aid of Korsgaard's theory. These two ideas help explain how even the slightest moral wrongs can be the cause of all the nervousness and worry observed in the scrupulous person.

First, if you are shaped by the choices that you make, then you are something uncomfortably precarious. According to Korsgaard, man is the only animal who has the task of creating his own form. In other words, each human being makes herself into a unique person. ${ }^{23}$ Your practical identity is a one-of-a-kind work of your own making. It is thus more intimately and fully yours than the deliveries of nature. Though this sounds romantic, it is also a sobering idea. Not only does it mean that you and you alone are responsible for making yourself into the person that you are, but it means that when you choose, you are working without a net. One false move and the project is marred. Outside the self you construct for yourself, there is no default state on which to fall back. This is because, per Korsgaard, your actions and your actions alone constitute your practical identity. ${ }^{24}$ If you make a misstep, then that misstep will be part of you.

To understand how this sense of precariousness contributes to scrupulousness, the metaphor of the tight-rope walker working without a net is both helpful and misleading. It is misleading in that, while a single ethical slip does leave a mark, it need not have catastrophic

\footnotetext{
${ }^{23} \mathrm{Id}$. at 129-30 ("Because he is alive in a further sense, then, a person has an identity in a further sense. He has an identity that is constituted by his choices. ... Every person must make himself into a particular person.”).

${ }^{24}$ See id. at 23 ( [Y]ou can walk out even on a factually grounded identity like being a certain person's child or a certain nation's citizen ....”).
} 
consequences for your practical identity. Korsgaard thinks that practical identity has inertia; so one immoral action does not make one an immoral person. ${ }^{25}$ The metaphor is helpful though in that it emphasizes that there is no content apart from your choices on which to fall back. So when one does make an immoral choice, however small it may be, it raises hard questions about the sort of person you are. Just like a tight rope walker who makes a misstep, wobbles, and looks down, the person who commits a minor unethical act glimpses the fragility of his practical identity.

He glimpses the fragility of his practical identity in the small immoral choice because he sees the potential both for bad action and to become a bad person by repeated bad actions. The potential exists because he is a free being constituted by his own choices. Remember that people usually like to think of themselves as decently moral individuals. A person may even take pride in the fact that he is loyal or kind. However, if Korsgaard is to be believed, then he his only those things to the extent that he chooses to make himself loyal and kind. If he insensitively shouts at a clumsy coworker, then his kindness is called into question. Truly, he does not thereby cease to be a kind person. Yet, like the tight-rope walker who shudders after seeing the ground below, he perceives in his act the fact that it is only his own free choices that separate him from being a callous, wrathful person. ${ }^{26}$

\footnotetext{
${ }^{25}$ The self for Korsgaard is a work-in-progress to which each new action contributes; it is not created anew with every fresh choice. See id. at 35-36.

${ }^{26}$ In using words like "kind," "loyal," "callous," or "wrathful,” I do not mean to renege on my earlier commitment to treating moral stains as non-psychological properties of individuals. To use these words consistently with that commitment, however, I must ask the reader to understand them not as expressing actual psychological traits (e.g., the warm feeling typical of the kind person) but as states of persons whose actions have corresponded to these traits. Thus, in this manner of speaking, the kind person is not necessarily kind in the sense that he is disposed to warm feelings and finds it easy to lend a helping hand; rather, he is a person who has done kind things and thereby, on the Korsgaardian theory, constituted himself a kind person.
} 
This possibility is all the more keen since it lies in his own freedom. His abusive action showed him how easily he may make a wrong decision. Just as a tight-rope walker may, in a flash, make a misstep, a person may make a moral misstep all the more easily. He can do so as fast as he can will: he need only decide to let an immoral principle govern his actions. Furthermore, since his choice is free, it is surrounded with a kind of mystery. What made him choose wrong over right in this instance? If he is free (as Korsgaard understands that concept), then ultimately the answer can only be that he chose to act immorally. This intensifies the feeling of fragility because thinking of the capriciousness of his own will emphasizes to him how precarious his self-constituted personhood is.

Catching a glimpse of the precariousness of one's practical identity is part of what explains the scrupulous person's sensitivity over minor ethical violations. To make the point concrete, we can consider our student Emily. When she is arguing with herself over the morality of her actions weeks ago on test day, she might think (supposing her internal prosecutor has gotten the advantage for the moment), "No, what I did was wrong. But, does that mean that I am a cheater? I've never done anything like that before, and I won't do it again . . . I hope ... but there's still some bad in me that made me do that. Can I really truthfully say that I'm an honest person, honest deep down?” For Emily, her worries about who she is “deep down” stem from a sense of the insecurity of her practical identity, an insecurity perceived in the minor transgression that she worries she has committed.

The second idea is that scrupulousness is driven by a melancholy perception of loss in the immoral action and consequent moral staining. It is melancholy because it is a harm to 
something irreplaceable, the damage done to which is (seemingly) irrevocable. ${ }^{27}$ Put more poetically, a person who has done something immoral may feel that he has lost himself. Since the immoral action has stained him, he worries he can never be the person he had been or had aspired to become.

For an explanation of the feeling of loss, ostension will have to substitute for analysis. Consider a family heirloom such as a diary written by your great-grandmother. Suppose that you are looking through the diary and come across an interesting story. As you pick up the old book, you accidentally knock a bottle of liquid paper over on to the page. The text you were so excited about reading is now crisscrossed with white liquid. At a moment like this, you'll probably have a sinking feeling in your stomach. It is a different feeling than the one you would experience if you spilled red wine on an expensive new coat. While the coat can be replaced, your greatgrandmother's diary cannot. It is also a different feeling than you would have if in your haste you had ripped the page. Whereas the paper can be mended, the white liquid cannot be removed. In sum, blotting out the text occasions a special kind of sorrow because the words are believed to be lost forever.

Second, consider an Olympic sprinter who stumbles off the starting block at the big race. Although he is only thirty years old, he is an old man by the standards of his sport. He has been running all his life but this is his first and likely only trip to the Olympics. Growing up, he was always told what a talent he had for running, and from an early age, he himself realized what amazing potential he had as an athlete. His awareness of that potential helped fuel his ambition;

\footnotetext{
${ }^{27}$ As I interpret Korsgaard, practical identity has “inertia” but is nonetheless malleable. That said, cleaning up one’s practical identity is not a topic that Korsgaard specifically addresses. In a later section, I will suggest that our bad actions are not a permanent part of our identity but that a theory of repentance is necessary to explain how they may be excised. For now, it is sufficient to say that, even if the stain can be erased, it has sufficient special stickiness to make a person feel as if he has perpetrated an irrevocable harm.
} 
he always hoped to win a medal at the Olympics in order to prove his greatness as a sprinter. When this person stumbles as the critical moment, the loss is an especially doleful one. He is grieved not only because he lost this particular race but because he feels he has lost himself. Kierkegaard describes this experience when he speaks about the "the ambitious man whose slogan is 'Either Caesar or nothing." 28 When this man "does not get to be Caesar, he despairs over it." "29 "[H]e does not despair because he did not get to be Caesar but despairs over himself because he did not get to be Caesar.”30

For the scrupulous person, the same feeling of loss makes even small ethical lapses take on outsized significance. This helps explain why she is so nervous about miniscule ethical violations. Though the black marks on her identity are small, they are there permanently. If an heirloom vase is chipped, the piece can be reattached with glue, but a crack will remain. The vase can never be fully restored. Similarly, a scrupulous person sees in petty unethical actions minute cracks in her self. Just like in the case of the vase, an abiding loss has occurred, one that carries it with it the same unique flavor of melancholy observed in the cases of the diary and the sprinter.

Let's consider Emily again. Suppose that she has convinced herself for the time being that what she did was immoral. Instantly, she resolves never to repeat her mistake. "But, can that really take away what I have done," she frets. "Years from now, I will still be the person who

\footnotetext{
${ }^{28}$ Soren KierkegaARd, The SicKNess Unto DeAth. 19 (Trans. Howard V. Hong and Edna H. Hong, 1980). When this man "does not get to be Caesar, he despairs over it." Id. "[H]e does not despair because he did not get to be Caesar but despairs over himself because he did not get to be Caesar.” Id.

${ }^{29} I d$.

${ }^{30} I d$.
} 
cheated.” "Maybe I can make up for it by giving to charity . . ..” Emily’s worry here is that her bad action has left a permanent mark on her. Its irreversibility depresses her. She may seek solace in forgetfulness; she might think, "I wish I could stop thinking about this, but then, I'd just be hiding the truth from myself, and besides, you can never really forget something if you're trying to forget it.” In the alternative, she thinks about what she could do to erase it (ponders supererogatory acts, confession, etc.). The sadness she feels is the sadness of a permanent loss. Like the sprinter who feels he has lost himself because he can never be the great sprinter he thought himself to be, Emily feels she has lost herself because of the ethical black mark on her self.

I promised a discussion of repentance. One of the reasons the scrupulous worry about ethical staining is that the stain is regarded as permanent. In my discussion of the sense of loss accompanying moral staining, I provisionally credited these beliefs and described moral stains as permanent or irrevocable. However, this is inconsistent with Korsgaard's theory. She says, “Constructing, creating, shaping, reshaping, maintaining, improving, in all these ways constituting this kind of identity is the everyday work of practical deliberation." ${ }^{31}$ Korsgaard does not specify to what extent we can reshape our practical identities, much less consider to what extent we can excise bad actions from them. However, the word "reshape" encompasses the possibility that practical identity, over time, can be wholly reformed and bad actions extirpated. Insofar as this is Korsgaard's position, I agree—-but with reservations.

My reservation is that Korsgaard's position makes it too easy to uproot past misdeeds from our practical identities. Namely, expungement of immoral actions must involve something

${ }^{31}$ KoRSGAARD, supra note 3, at 129 (emphasis added). 
more than a resolution, made good upon, to be better in the future. Otherwise, one cannot make sense of the human urge to pursue more purposeful forms of atonement. I have in mind confession, supererogatory acts, self-denial of the fruits of a crime, and collateral forms of selfimposed austerity. A good theory of repentance should account for these phenomena.

Such a theory of repentance would explain how moral stains may be expiated. Still, such a theory would require much more of the individual than mere regret and a successful resolution to do better in the future. Thus, while moral stains would not be strictly speaking permanent, they would possess a durability (and an apparent permanence) sufficient to account for the melancholy feeling of self-loss associated with small ethical infringements. As for the content of such a theory of repentance, the matter is beyond the scope of this paper.

I set out to answer the question: why is it that minor ethical infringements can occasion so much anxiety after the act? My answer is that scrupulousness is anxiety over moral staining. But what is moral staining? Korsgaard propounds that personal or practical identity is constructed by our actions. Thus, immoral actions become a part of who one is. On Korsgaard’s theory, you literally construct yourself via your actions. Thus, the staining metaphor captures the effect of bad actions on the self.

If we keep Korsgaard's theory of self-constitution in mind, it is understandable for a person to fret about the effect unethical actions have on who she is. In short, unethical actions cannot be written off as past mistakes but follow you into the future because they form a part of you. When someone like Emily worries that she has already done wrong, her desire to know whether or not this is true of her (that she has stained herself) drives her to conduct the exercises in applied ethics that we see driving her to distraction. As I said however, this does not 
completely explain scrupulousness because it does not account for the lack of proportionality between the size of the ethical errors and the harried nerves of the scrupulous individual. There are two reasons small ethical slips take on such outsized significance for the scrupulous person. The first is that they reveal the fragility of your personal identity so that you face painful questions about who you really are “deep down.” The second is that moral lapses, however small, still leave permanent black marks. This inspires a melancholy sense of loss akin to that felt when a vase is chipped. Just as you may be touched with sorrow at the thought that the vase can never be the same again, you may feel a like sorrow at the thought that an unethical action has permanently altered you.

\section{Two Theories of Guilt}

Guilt understood as a moral stain is both distinct from and has advantages over another, more prevalent view of guilt — that of guilt as consisting in the rupturing of valued relationships with others. I compare the two to show that the staining view is unique and that it accurately captures the phenomenology of guilt as a reflexive, inward phenomenon. The version of the severance view I describe is that of Herbert Morris. ${ }^{32}$

According to Morris, the "concept of wrongdoing” is connected with the concept of "being joined together with another or others, the idea of union." ${ }^{33}$ In this union, "one is complete, one is whole, in a way that one would not be without it." 34 Wrongdoing (when yoked with fault) embodies the severance of these connections. ${ }^{35}$ Given that one's own integrity is dependent on these connections with others, their severance also entails a painful self-sundering.

\footnotetext{
${ }^{32}$ Herbert MORRIS, Guilt and Suffering, in On GuILT AND INNOCENCE, 89, 96-97 (1976).

${ }^{33} \mathrm{Id}$. at 96 .

${ }^{34}$ Id.

${ }^{35} I d$. ("When one is guilty of wrongdoing, one separates oneself from another or others with whom one was joined.”).
} 
The severance view emphasizes that ideas about wrongdoing exist side-by-side with notions of restoration. ${ }^{36}$ Thus, practices such as "receiving forgiveness, making sacrifices, reparation, and punishment” are significant as "rite[s] of passage back to union.” ${ }^{37}$ These are importantly rites of passage because they accomplish what mere forgetting does not: "For restoration there must be a bringing back by certain appropriate responses which carry significance for the parties." 38 This is because, “A wrong . . . is not understood as righted when matters are simply where they were before the wrong . . . "39

Like guilt as moral staining, guilt as estrangement distinguishes between guilt and guilt feeling. ${ }^{40}$ I agree with separating the two. One can be guilty without feeling guilty, perhaps because one does not believe oneself to be guilty. More typically, one believes oneself to be guilty (because one is guilty) and consequently feels guilty. Of course, if you believe you are guilty, you might also feel guilty, regardless of whether or not you are in fact guilty. Per other permutations, one can feel guilty without believing oneself to be guilty, both when one is, and when one is not, in fact, guilty.

These combinations aside, differentiating feeling guilty and being guilty is significant because it allows one to recognize what Martin Buber called guilt’s “ontic character” as something "whose place is not the soul but being." 41 Both the severance and the staining views recognize guilt's ontic character. Where guilt as estrangement differs from guilt as moral staining is in the nature of that something "whose place is . . being." On the severance view, it consists

${ }^{36}$ Id. at $96-97$.

${ }^{37}$ Id. at 96.

${ }^{38}$ Id. at 97.

${ }^{39}$ Id. at 97.

${ }^{40}$ See id. at 89, 98-99.

${ }^{41}$ Martin Buber, Guilt and Guilt Feelings, in Guilt And Shame 58, 60 (Herbert Morris ed., 1971). 
in the real rupturing of relationships with others, relationships that themselves were crucial to the unity of the offending individual. In my view, it derives from the fact that actions are selfconstitutive, such that immoral actions form a part of you and leave you persistently tarnished.

Guilt as moral staining contrasts favorably with the estrangement view in at least one meaningful respect. To wit, moral staining better represents the self-concerned, self-occupied character of guilt. This quality of guilt is well-captured in the work of Gabriele Taylor on distinguishing guilt from remorse. Taylor, who also propounds a view of guilt as selfdisfigurement, distinguishes guilt from remorse by focusing her attention on the guilty individual's preoccupation with the removal of the burden of guilt he bears in contradistinction to the remorseful person's concern with remedying or recompensing harm done to others. Viewed in this light, guilt as estrangement mistakenly emphasizes severing of relationships and the urge to repair them, matters more typical (if we believe Taylor) of remorse than guilt.

Taylor writes of remorse: "The thought in remorse ... concentrates on the deed rather than on the agent as he who has done the deed." ${ }^{42}$ Remorse then is like regret for they both involve something ill which has come to pass, the occurrence of which is bemoaned or lamented. Remorse differs from regret though in that the former is "always felt about an event which the agent sees as an action of hers." ${ }^{43}$ While much regret is idle regret, remorse carries with it an expectation that the remorseful person will try to right the wrong they have done: ${ }^{44}$ Taylor explains, "The person feeling remorse is tied to her action as the person feeling regret is not. She must do something about it, or it will continue to worry her." ${ }^{45}$

\footnotetext{
42 TAYLOR, supra note 25, at 98.

${ }^{43} \mathrm{Id}$.

${ }^{44} I d$. at 99 .

${ }^{45} \mathrm{Id}$.
} 
Although the person feeling remorse "is tied to her action," her concentration is still on the harm she has done, not on herself. Taylor writes, "Remorse is not an emotion of selfassessment, the concentration of thought here is not on the self, on its disfigurement or lowly standing, but is on her actions and their consequences." ${ }^{46}$ The implication is that guilt, by contrast, is an emotion of self-assessment:

[E]ven where the person feeling guilt believes that she has harmed another and believes that she should now repair this damage, her thoughts are not primarily on this aspect of the situation, they are primarily on herself. In this sense, too, the thought of damage caused and so to be repaired is inessential. In feeling remorse, on the other hand, it is precisely these thoughts which are the agent's identificatory beliefs, i.e., when feeling remorse the agent believes that she has done harm which she ought to try and repair. ${ }^{47}$

Taylor's differentiation of guilt and remorse is incongruent with the severance theory, since according to Taylor, an emphasis on outward harm (e.g., broken relationships) is characteristic of, not guilt, but remorse. Compare the prior indented quote from Taylor with Morris' conclusion about guilt:

The central, though not the only, case of being guilty of wrongdoing is one in which one is both at fault and responsible for wrongdoing and thus is separated from others, obligated to them, and deserving of some hostile response from them. I say this case is central, for I believe that the concept is employed here with its full panoply of associated concepts, concepts such as being guilty before another or others, asking for and gaining forgiveness, and mending what has been broken. ${ }^{48}$

As I believe Taylor has shown, emphasis on broken relationships is misplaced in a theory of guilt. The urge to repair the harm done is typical of remorse, not guilt.

The reflexive turn in guilt is also visible in the phenomenon of guilt over harmless and unnoticed misdeeds. Situations in which one acts immorally, but the wrong is both undetected and innocuous, lend themselves better to the moral staining view of guilt than to the rupturing of

\footnotetext{
${ }^{46}$ Id. at 99-100 (emphasis added).

${ }^{47}$ Id. at 104.

${ }^{48}$ MORRIS, supra note 30, at 98 (emphasis added).
} 
relationships theory. The action of our scrupulous student Emily is one example of this genus of misdeeds. Suppose for a moment that what Emily did was in fact cheating and was in fact immoral. Still, she only cheated on one question of a high school geography exam, hardly a great injury or breach of faith with her teachers and classmates. The consequences of her action, the difference between earning an "A-" or an ill-gotten " $\mathrm{A}$ " on the exam, hardly seem worthy of remorse. And yet, if Emily truly did cheat, then she nonetheless has done something immoral and is guilty.

Other examples may be produced. If envy is in fact immoral, then a person who resents his friend's promotion has done something unethical, albeit only internally. We could also add unnoticed white lies or failed, unseen attempts to injure one's fellows. In another example, an ethical vegetarian is tempted to eat some leftover hamburger sitting in the family refrigerator. If he eats the surplus vittles, no harm will be done to an animal and no encouragement given to animal slaughter. Nonetheless, the ethical vegetarian may feel guilty (and arguably is guilty) after eating the leftover flesh. For all these cases, there is no apparent object of remorse, but there is nonetheless guilt.

The protagonist of Robert Coover’s novel The Universal Baseball Association is a particularly colorful example. The character is an accountant who in his spare time plays a game of his own invention, the eponymous Universal Baseball Association. It is a private form of fantasy baseball, in which players pitch and hit and teams win or lose according to elaborate rules befitting the man's mathematical profession. When the rules of the game dictate that his favorite player "die," the protagonist is thrown into a crisis. "Cheating” and letting the player live brings on feelings of guilt. Though we may question whether feelings of guilt are 
appropriate for the protagonist (i.e., whether anything immoral has actually been done), the example nonetheless highlights the inward looking, reflexive character of guilt.

Admittedly, the severance view possesses a means to account for these examples of guilt that is not other regarding. In his essay, Morris expressly recognizes that thoughts, which do not injure others, may nonetheless make one guilty. He says of such thoughts:

While conduct that is injurious to others is central to the concept of wrongdoing, it is important to note that certain relationships can be damaged by an individual's having a certain state of mind alone, a state incompatible with the relationship as it may be defined and valued. An intention to do an act that would betray a friend, for example, is itself a state that damages the relationship between friends. ${ }^{49}$

Thus armed, the severance view can attempt to account for the cases canvassed above in which guilt is present but harm is not. By telling a white lie, one fails to treat one's spouse with respect (one condescends by hiding the truth), and without respect, the relationship is compromised. Likewise, when one feels envy towards one's friend or secretly plots to harm her, the friendship is poisoned: the bond is broken even though only one side is aware of it.

In responding to cases of unseen, unfelt wrongs however, the theory of guilt as the severance of relationships must strain and become unintuitive. For example, supposing for a moment that Emily is actually guilty, one would need a story either about trust or about a communal practice—e.g., academic achievement or competition—-that loses its significance for Emily once she cheats. By failing the trust or subverting the practice, Emily would be cut-off from the corresponding community. Although this is a plausible account of how someone like Emily might experience guilt if she was invested in the relevant communal values, it fails to account for cases in which Emily cares little for grades and academics but nonetheless believes

\footnotetext{
${ }^{49} I d$. at 97.
} 
that cheating is wrong, perhaps because it is a species of dishonesty. In these latter cases, it is hard to imagine the severance view agreeing with the phenomenology of Emily's guilty mind.

Perhaps the reason that the severance theory has difficulty accounting for harmless guilty deeds is that it takes "conduct that is injurious to others [to be] central to the concept of wrongdoing." ${ }^{50}$ In the alternative, we might say as Taylor does, that it is sufficient to be guilty to have violated a law or command. ${ }^{51}$ The violation of a law is distinct from whatever harm that violation may or may not have caused. ${ }^{52}$ “[T] he person who feels guilty thinks in terms of duties not performed and obligations not fulfilled.”53 She need not think in terms of harm caused. Contra the severance view, harm to others is not central to guilt. Rather, the notion of a violation of an obligation is essential and salient.

Unlike a theory of guilt as the severance of relationships, guilt as moral staining need not strain itself to account for guilt arising from mere breach of moral obligation. On the contrary, a hidden, innocuous violation of moral law is an action of the individual that stains the self, regardless of the consequences for others or for one's unity with the community. The wrong done may have passed completely unseen or even have produced good results in the world, but for the individual facing herself in her own thoughts, there remains the fact of having chosen an immoral action that remains a part of her.

\footnotetext{
${ }^{50}$ Id. at 97.

51 TAYLOR, supra note 25, at 85. In truth, Morris does say that wrongdoing entails the "conception of some limit on conduct.” MORRIS, supra note 30, at 94. He believes though that the idea of a limitation on conduct is derivative of concerns about harm to those things that are valued. Id. at 93-94. Hence, harm is still the primary concept defining wrongdoing for Morris.

52 TAYLOR, supra note 25, at 86.

${ }^{53} \mathrm{Id}$. at 87.
} 
The goal of this section has been to recommend moral staining as a theory of guilt. I have chiefly championed it for matching the phenomenology of guilt. In this regard, I believe it compares favorably with Morris' severance theory as it accurately treats guilt as an inward, selfdirected phenomenon rather than an external harm-focused one. It also has much to recommend it as a "secular theory of sin," reflecting the experience of guilt as a perduring res that lies behind the widespread religious concepts of sin and karma. Alongside the phenomenological discussion, I have more timidly adopted a metaphysical view. As I stated, I agree with Morris that guilt corresponds to something real in the world. This position was implicit from the beginning of the paper. I initially specified that a moral stain is not external (the property of having performed action $y$ at time $x$ ) and excluded a character ethics interpretation. Instead, I characterized a moral stain as an internal property, and by adopting Korsgaard's view that the self is continually constituted by one's choices, sought to explain what such a property could be. For the reader who is unconvinced by these metaphysical claims, the theory of guilt as moral staining will hopefully commend itself nonetheless as an accurate piece of moral psychology.

\section{Postscript: Scrupulousness as a Character Trait}

The explanation I have given of scrupulousness should not be considered as a justification. On the contrary, I think that it is a dysfunctional and unhealthy psychological phenomenon: the nervousness of the scrupulous person is a source of discontent and suffering; her characteristic back-and-forth casuistry is a distraction from other concerns, moral and nonmoral, with a claim to her attention; and the intractability of the scrupulous person's internal moral debate witnesses to the casuistry's ineffectiveness as a source of correct moral understanding. 
The foregoing assessment of scrupulousness notwithstanding, further exploration of its merits yields some interesting, contrasting results on the value of moral worry to functioning as a moral agent. On the one hand, being scrupulous may make one a kind of moral coward, the kind of person who shies away from ethically ambiguous situations to avoid the anticipated pain of scrupulous doubt in the aftermath. On the other hand, care in avoiding moral gray areas might result in an overall improvement in one's conduct.

To see how scrupulousness could engender moral cowardice, consider the case of a young doctor who is about to complete her training. Part of her wishes to continue practicing in the city hospital where she has been serving as a resident. At the same time, she possesses the talent and inclination to take up an offered fellowship in medical research. Weighing her options, the fledgling doctor knows from experience that the demanding, chaotic work of the underresourced hospital has often placed her in circumstances where she suspects herself of small sins. For instance, she finds herself questioning whether her desire for sleep at the end of a twelve-hour shift overbore her professional obligations when she left work three minutes early instead of treating one more patient. Whereas other, non-scrupulous doctors would never give the matter a second thought, these situations frequently leave our young doctor struggling for weeks after over the morality of her choices: she finds herself questioning whether she did "all she could have done" or rather all she "ought to have done." On the other side of the fence, a daily life of academic speculation and experiments promises few occasions to precipitate scrupulous second-guessing.

Suppose now that when she makes her decision, it is the expectation of scrupulous suffering that makes the difference in her choice of the research fellowship. Though she is otherwise convinced that continuing to act as physician to the underserved would be the better 
course (we may even allow that it is the better choice), her fear of the chronic moral doubt and anxiety to be found on a path fraught with moral ambiguity steers her aside. Alternatively, we could imagine that her trepidation influences her decision-making at an earlier stage: before she made her decision, her fear may have caused her, gradually and unconsciously, to exclude remaining at the hospital as a live option.

Though the word “coward” is perhaps unduly shaming, we might call the physician’s condition in either case "moral cowardice” on an analogy to physical cowardice. As I have argued, the scrupulous person's worries are explained by anxiety over moral staining. It is thus inappropriate fear of "moral injury" that ultimately steers the moral coward away from moral ambiguity, just as the physical coward's undue fear of bruises or broken bones keeps her from snow skiing or serving as a firefighter.

I take the fear of moral injury to be inappropriate because it is, at best, only a minor reason. Were it given much weight as a reason, the best course for an agent would too often be one of passivity, e.g., "stay at home where you can’t sin.” In the case at hand, I assume that the risk to one's own moral purity ceteris paribus cannot outweigh the good to be done by the physician in the inner city hospital.

The idea of moral cowardice notwithstanding, it is possible to paint the moral worry of the scrupulous person in a positive light. In some cases, avoidance of moral ambiguity looks like a good habit. Consider the case of our student Emily. Having suffered from scrupulous doubt as a result of her unintended glance at the geography book stuffed into her backpack, she will be more careful in the future to keep her textbooks well out of sight before a test begins. By thus 
avoiding moral ambiguity, Emily dodges making difficult, close moral judgments. The ultimate result is that Emily improves her odds of maintaining a record of right conduct. ${ }^{54}$

Given her fear of scrupulous doubts in the aftermath of a morally ambiguous decision, Emily is attentive to such situations. This is in itself salutary because it is helpful for a moral agent to have notice of those morally grey circumstances that call for her attention and care, both so that she may avoid them when appropriate and so that she may recognize them and deliberate when they are upon her. The alarm that scrupulousness raises is, however, not a mild alert but a screeching disincentive to encounter with moral ambiguity.

It is this metaphorical screeching that distorts the choices of the young doctor. By psychological brute force, it infringes on her judgment as to the normative-ethical merits of her situation. The strident moral alarm that scrupulousness imbues one with does not furnish one with good reasons to avoid moral ambiguity. Putting the point more concretely, the fear of scrupulous doubt experienced by the doctor (her alert to the prospect of encountering moral ambiguity in the hospital job) is not itself a significant reason for or against taking the research job as opposed to the hospital job. As we saw, however, it had a decisive impact on her decision making process, and a decision that should have been made on the normative-ethical merits (the good and bad of taking one job over the other) was instead decided by a fear that was itself blind to those merits.

To conclude, while scrupulousness may sometimes have a positive result (greater moral caution), the caution it engenders is not reliably calculated to help an agent respond correctly to

\footnotetext{
${ }^{54}$ In a similar vein, Ruth Barcan Marcus has argued that agents ought to arrange their affairs to avoid moral dilemmas. Ruth Barcan Marcus, Moral Dilemmas and Consistency, 77 J. PHIL. 121, 121 (1980).
} 
moral ambiguity. On the contrary, fear of anticipated scrupulous suffering is apt to interfere unreasonably with an agent's decision making.

As a final note, it is curious that even though scrupulousness is a vice, it is nonetheless a vice of the virtuous. Both our imaginary doctor and our student Emily are people who care a great deal about doing the right thing. It is only because concern for poor patients looms so large in the mind of the doctor that she is confronted with the choice between the nerve-wracking hospital work and the research fellowship. A more selfish doctor would certainly exclude the former in favor of the profits of private practice! Emily, similarly, must care a great deal about honesty and academic integrity to even question the morality of answering a test question after a revealing, inadvertent glance at her books. Remarkably, scrupulousness appears in a double guise, a vice in its own right but a mark of virtue as well. 